\title{
Prevalence of asthma among school children in Gaborone, Botswana.
}

\author{
Andrew Kiboneka ${ }^{1}$, Michael Levin ${ }^{2}$, Thembisile Mosalakatane ${ }^{1}$, Ishmael Makone ${ }^{3}$, Eric Wobudeya ${ }^{4}$, \\ Boikanyo Makubate $^{5}$, Russell Hopp ${ }^{6}$, Loeto Mazhani ${ }^{1}$, Shiang-Ju Kung ${ }^{7}$
}

1. Department of Paediatrics \& Adolescent Health, Faculty of Medicine, University of Botswana, Gaborone, Botswana.

2. Allergy Division, Department of Paediatrics \& Child Health, University of Cape Town and Red Cross Memorial Children's Hospital, South Africa.

3. Department of Paediatrics \& Adolescent Health, Princess Marina Hospital, Gaborone,Botswana.

4. Directorate of Paediatrics \& Child Health, Mulago National Referral Hospital, Kampala, Uganda.

5. Department of Mathematics \& Computational Sciences, Botswana International University of Science

\& Technology Palapye, Botswana

6. Division of Allergy/Immunology, Creighton University Medical Centre, Omaha, Nebraska, USA.

7. Division of Allergy \& Immunology, Children's Hospital of Philadelphia, Pennsylvania, USA.

\begin{abstract}
Background: Asthma prevalence is high $(>10 \%)$ in developed countries and although data is still missing for most of Africa, rates are increasing in developing regions as they become more westernized. We investigated the prevalence of asthma in school children in Gaborone, Botswana.

Methods: This was a cross sectional descriptive study. ISAAC methodology was used. A representative proportionate size random sample of two age groups of children (13-14 year olds and 6-7 year olds) was consecutively enrolled from 10 schools. The schools were selected using a table of random numbers. A minimum sample size of 924 individuals (462 from each group) was adequate to achieve a precision of $3 \%$ around our estimated prevalence of asthma of $10 \%$ with $95 \%$ confidence assuming a non-response rate of 20\%. Data was collected using the validated International study of Asthma and Allergies in children (ISAAC) questionnaire. In accordance with the ISAAC criteria, Asthma was defined as wheezing in the previous 12 months. Data was captured in microsoft excel and analysed using SPSS version 23.

Results: The prevalence of asthma (wheezing in the previous 12 months) was 16.5\% (194/1175). Among the 6-7 year olds, the prevalence of asthma (wheezing in the previous 12 months) was $15.9 \%$, while among the 13-14 years olds it was $16.8 \%$. The prevalence school type was $22.3 \%$ in private schools versus $14.5 \%$ in public schools. More severe asthma was associated with older children, 13 -14 years. The older children reported more limited speech due to wheezing $(\mathrm{OR}=2.0,95 \% \mathrm{CI}=1.034,3.9$, $\mathrm{p}$-value $=0.043)$, ever had asthma $(\mathrm{OR}=1.5,95 \% \mathrm{CI}=1.031,2.3$, $\mathrm{p}$-value $=0.034)$ and wheezing during exercise $(\mathrm{OR}=3.4,95 \%$ $\mathrm{CI}=2.5,4.9$, $\mathrm{p}$-value $=<0.001)$ compared to the younger children 6-7 years. Children from private schools had more wheezing symptoms. They were more likely to have ever wheezed $(\mathrm{OR}=2.2, .95 \% \mathrm{CI}=1.7,2.9, \mathrm{p}$-value $<0.0001)$, wheezed in the previous twelve months (have asthma) $(\mathrm{OR}=1.7,95 \% \mathrm{CI}=1.2,2.4$, $\mathrm{p}$-value $=0.001)$, ever had asthma $(\mathrm{OR}=2.4,95 \% \mathrm{CI}=1.7,3.5, \mathrm{p}-$ value $<0.0001)$, and wheezed during exercise $(\mathrm{OR}=1.8,95 \% \mathrm{CI}=1.4,2.4$, $\mathrm{p}$-value $<0.0001)$.
\end{abstract}

Conclusion: The prevalence of asthma amongst school children in Gaborone, Botswana is high with older children experiencing more severe symptoms of asthma.

Keywords: Children, asthma, prevalence, school

DOI: http://dx.doi.org/10.4314/ahs.v16i3.22

Cite as: Kiboneka A, Levin M, Mosalakatane T, Makone I, Wobudeya E, Makubate B, Hopp R, Mąhani L, Kung S-J.Prevalence of asthma among school children in Gaborone, Botswana. Afri Health Sci 2016;16(3): 809-816. DOI: http:/ / dx.doi.org/10.4314/abs.v16i3.22

\section{Corresponding author:}

Andrew Kiboneka,

Department of Paediatrics \& Adolescent Health,

Faculty of Medicine, University of Botswana,

Gaborone, Botswana.

Email: akiboneka@yahoo.com

\section{Background}

Asthma is a common chronic disorder of the airways that is complex and characterized by variable and recurring symptoms, airflow obstruction, bronchial hyper-responsiveness, and an underlying inflammation ${ }^{1}$. The latter has implications for the diagnosis, management and potential prevention of the disease ${ }^{1}$. Asthma is the 14th

African Health Sciences Vol 16 Issue 3, September 2016 
most important chronic disease in the world in terms of the prevalence, extent, and duration of disability, affecting 334 million individuals of all ages ${ }^{2}$. In the industrialised countries, asthma prevalence ranges from $10 \%$ to $25 \%{ }^{2}$. In developing regions of Africa, Central and South America, Asia, and the Pacific, asthma prevalence continues to rise sharply with increasing urbanization. Estimates suggest that more than 50 million individuals in Africa currently have the disease ${ }^{3}$. The prevalence in Africa has been reported ranging from $18 \%$ in Kenya to $20 \%$ in South Africa ${ }^{4}$.

Observations that developed countries show higher prevalence of asthma than developing countries have led to the "hygiene hypothesis," which postulates that childhood development in an overly hygienic environment reduces microbial exposure and promotes atopic immune responses and the risk of asthma ${ }^{5}$. The original hygiene hypothesis' was prompted by evidence that overcrowding, unhygienic conditions and larger family size were associated with a lower prevalence of atopy, eczema, hay fever and asthma ${ }^{6}$ Increased infections and exposures to microorganisms and/or their components, particularly early in life, have been proposed as an explanation for these finding. The immunological explanation has been put into the context of the functional $\mathrm{T}$ cell subsets known as T helper 1 (TH1) and T helper 2 (TH2) that display polarized cytokine profiles.

It has been argued that bacterial and viral infections during early life direct the maturing immune system toward TH1, which counterbalance proallergic responses of TH2 cells. Thus, a reduction in the overall microbial burden will result in weak TH1 imprinting and unrestrained TH2 responses that allow an increase in allergy. Our study done in Gaborone, Botswana an urban environment may therefore reveal a high burden of asthma in these school children especially those attending private schools as opposed to public schools. A study in the USA showed that odds of asthma were greater with decreasing socioeconomic index ${ }^{8}$. Here the burden of asthma is highest among socioeconomically disadvantaged populations; however, its impact is differentially distributed among racial and ethnic groups

A recent systematic review reported prevalence and time trends of wheezing symptoms among children, both worldwide and within the same country 9 .

A wide range of current prevalence of wheeze was observed between and within countries over time. The UK had the highest recorded prevalence of $32.2 \%$ in children aged 13-14 in 1994-5 and Ethiopia had the lowest prevalence, $1.7 \%$ in children aged 10-19 in 1996. There were no studies done in Botswana.

The younger age group has been chosen to give a reflection of the early childhood years, when asthma is common, and admission rates are particularly high. However some centres may not have the resources to proceed with the younger age group. The older age group has been chosen to reflect the period when mortality from asthma is more common. School children are the most accessible people of any age group.

Asthma prevalence rates differ between various population groups, particularly when using different methodologies. Hence in 1991, the International study of Asthma and Allergy in Children (ISAAC) was initiated, in an attempt to address the growing concern that atopic disorders, namely asthma, rhinitis and eczema, are increasing in both westernized and developing countries ${ }^{10}$. ISAAC, using a simple and inexpensive standardized methodology, has been implemented in four phases.

A history of recurrent episodes of wheezing is universally accepted as the starting point for asthma diagnosis in children ${ }^{11}$.

Data from ISAAC phase I questionnaire based surveys, conducted seven years apart, centred on self-reported symptoms of asthma in 13- to 14-yr-old school adolescents in Cape Town and showed increases in the 12 -month prevalence of wheezing (16\% vs. $20.3 \%$ ), exercise-induced wheeze $(21.5 \%$ vs. $32.5 \%)$, nocturnal cough $(23.6 \%$ vs. $36.6 \%)$, sleep disturbance due to wheeze $(9.6 \%$ vs. $16 \%)$, or severe wheeze $(5.1 \% \text { vs. } 7.8 \%)^{4,10}$.

In general, although data on paediatric asthma is increasing worldwide, asthma data from Botswana is limited. Literature search by PubMed shows one publication from 1997, referring to adult Batswana patients, in whom asthma contributed to $1.9 \%$ admissions and $0.7 \%$ of inpatient deaths ${ }^{12}$. However, this adult study examined pa- 
tients seeking medical care in specific locations. Hence, there are no studies to date to adequately delineate asthma prevalence within the general population of Botswana. Our study aimed to determine the prevalence of asthma in school children aged 6-7 and 13-14 years in public and private school children in Gaborone, Botswana. Our study is important as it provides baseline data on asthma prevalence in children in Gaborone and Botswana. This in-turn informs policies and guidelines for asthma control.

\section{Methodology}

Study design: This was a descriptive cross sectional study. The study methodology was in line with the ISAAC's study recommendations ${ }^{13}$.

Study setting: The study was conducted in randomly selected public and private primary and secondary schools of Gaborone. We included school children aged 6-7 years in the selected primary schools and 13-14 years in the secondary schools. Gaborone, the capital city of Botswana, is located in the South East region and has a total population of 231,592 and an average income per capita of Pula 16,272 (1953.42 US dollars) with a literacy rate of $92 \%{ }^{14}$. There are 28 secondary schools and 47 primary schools in this region. The age range in the primary schools is 6 to 12 years while that in the secondary schools is 13 to 17 years. The estimated size of the population across all schools, aged 6-7 years in the primary schools is 4987 while that of children aged 13 - 14 in secondary schools is 4426 .

\section{Sampling and data collection:}

The sampling frame was all the primary and secondary schools in Gaborone. The schools were stratified by level as primary (for 6-7 years) or secondary schools (for 1314 years). The stratified schools were allocated numbers. The sampling unit was a school for each age group. The schools to recruit from were selected using a table of random numbers. We selected 20 schools of which ten were primary schools and ten were secondary schools. Two classes were chosen from each of the selected schools. The chosen two classes that had the greatest proportion of 13 year olds and 14 year olds (for secondary schools); those with the greatest proportion of 6 year olds and 7 year olds (for primary schools) were considered for re- cruiting study participants. The children to study were randomly selected from the chosen classes basing on class register numbers. Of the twenty schools, thirteen were public schools, whilst seven were private schools.

Data was collected using pre-tested modified ISAAC questionnaire in English or Setswana translation. The research assistants were trained prior to data collection. The questionnaires were self-completed by the parents of the children 6-7 years and by the children themselves or research assistant in the older children (13-14 years). The self-completed questionnaires were collected within 7 days of providing them to the children by the research assistant. The parents with unreturned forms were followed up by phone or visited at home. Asthma case was defined based on the ISAAC criteria of wheezing in the previous 12 months.

Data management and statistical analysis: Using the Kish Leslie formula with design effect of 2.0, assuming a prevalence of asthma of $10 \%{ }^{3}$, with a $\pm 3 \%$ precision around the estimated prevalence of asthma with 95\% confidence, we estimated that a minimum sample size of 770 individuals (385 from each group) was adequate. The final estimated minimum sample adequate for this level of precision was adjusted to 924 (462 from each group) to account for $20 \%$ non-response rate. Data was entered into microsoft excel. Discrepancies were investigated and resolved by reviewing the questionnaire and correcting the erroneous data entry record to reflect the participant response. SPSS version 23 was used for both data management and analysis. Descriptive statistics were used to report the demographic data of participants. The prevalence of asthma was reported as a proportion. Severe asthma was defined as limited speech or disturbance of sleep. Any differences between categorical variables were assessed using the Chi-square test. P values less than 0.05 were deemed statistically significant.

\section{Ethical issues:}

Ethical approval was obtained from the Health and Research Development Committee (HRDC) of the Ministry of Health, as well as research clearance from the Ministry of Education, prior to commencement of study. Institutional consent was obtained from all the schools before commencement of the study. Written informed consent 
was obtained from the parents/guardians of the children as well as assent from children of 13-14 years. Privacy \& confidentiality of participants was maintained.

Participants who wished to withdraw from the study could do so at any point of the study. There were no unique identifiers in the database that could be easily linked to a participant. Participants were each assigned a unique identification number based on their school. This number was for the study purposes only and could not be linked to an individual household. Children found with asthma were brought to the attention of the school nurse for further care.

\section{Results}

The recruitment was done between October 2014 and November 2015. We sampled 1975 children; 835 (42.3\%) from primary schools and $1140(57.7 \%)$ from secondary schools. Of the sampled 1975, $665(33.7 \%)$ children were from private schools while 1310 (66.3\%) were from public schools.

Of the 1975 children, 1175 were enrolled in the study giving a response rate of $59.5 \%$. Three hundred fifty eight $(30.5 \%)$ of the respondents were from primary schools while 817 (69.5\%) were from secondary schools. A total of $310 / 1175(26.4 \%)$ participants were from private schools. See Table 1.

\section{Table 1: General characteristics of the studied school children in Gaborone, Botswana ( $N=1175)$}

\begin{tabular}{lll} 
Variable & N & $\%$ \\
School category & & \\
\hline Primary (6-7 years) & 358 & 30 \\
\hline Secondary(13-14 years) & 817 & 70 \\
School type & & \\
public & 865 & 74 \\
Private & 310 & 26
\end{tabular}

Wheezing was reported by $316 / 1175(26.9 \%)$ children: $88 / 358(24.6 \%)$ were primary school children, whilst 228/817(27.9\%) were secondary school children.
The proportion reporting wheezing in the previous 12 months (asthma cases) is $16.5 \%(194 / 1175)$. There were $60 / 1175(5.1 \%)$ children whose wheezing had been severe enough to limit their speech. See Table 2 for more details.

\section{Table 2: The distribution of respiratory symptoms among the studied children in Gaborone, Botswana ( $\mathrm{N}=1175)$}

\begin{tabular}{|l|l|l|}
\hline Symptoms & Frequency & $(\%)^{\star}$ \\
\hline Ever had Wheezing & 316 & 27 \\
\hline Wheezing last 12 months & 194 & 17 \\
\hline Reported sleep disturbance due to wheezing & 44 & 3.7 \\
\hline Reported limited speech due to wheezing & 60 & 5.1 \\
\hline Ever had Asthma & 148 & 13 \\
\hline Wheezing during exercise & 318 & 27 \\
\hline Dry Cough at night & 283 & 24 \\
\hline Chronic Cough & 142 & 12 \\
\hline
\end{tabular}

*Greater than $100 \%$ due to multiple responses. 
Among the 6-7 year olds, the prevalence of asthma (wheezing in the previous 12 months) was, $15.9 \%$, while among the 13-14 years olds it was, $16.8 \%$. The preva- lence by school type was, $22.3 \%$ in private schools versus $14.5 \%$ in public schools. See more comparative details in Table 3.

Table 3: Distribution of respiratory symptoms by age group and school type among school children in Gaborone, Botswana $(N=1175)$

\begin{tabular}{|l|l|l|l|l|}
\hline Symptoms & \multicolumn{2}{|l|}{ Age group } & \multicolumn{2}{l|}{ School type } \\
\hline & $\begin{array}{l}6-7 \text { years }(\%) \\
(\mathrm{n}=358)\end{array}$ & $\begin{array}{l}13-14 \text { years }(\%) \\
(\mathrm{n}=817)\end{array}$ & $\begin{array}{l}\text { Public (\%) } \\
(\mathrm{n}=865)\end{array}$ & $\begin{array}{l}\text { Private }(\%) \\
(\mathrm{n}=310)\end{array}$ \\
\hline Ever had Wheezing & $88(25)$ & $228(28)$ & $109(13)$ & $33(10.6)$ \\
\hline Wheezing last 12 months & $57(16)$ & $137(17)$ & $125(15)$ & $69(22)$ \\
\hline $\begin{array}{l}\text { Reported sleep disturbance } \\
\text { due to wheezing }\end{array}$ & $17(4.7)$ & $27(3.3)$ & $34(3.9)$ & $10(3.2)$ \\
\hline $\begin{array}{l}\text { Reported limited speech } \\
\text { due to wheezing }\end{array}$ & $11(3.1)$ & $49(6.0)$ & $41(4.7)$ & $19(6.1)$ \\
\hline Ever had Asthma & $34(9.5)$ & $114(14)$ & $84(9.7)$ & $64(21)$ \\
\hline Wheezing during exercise & $45(13)$ & $273(33)$ & $205(24)$ & $113(37)$ \\
\hline Dry Cough at night & $74(21)$ & $209(26)$ & $197(23)$ & $86(28)$ \\
\hline Chronic Cough & $36(10.1)$ & $106(13.0)$ & $109(13)$ & $33(10.6)$ \\
\hline
\end{tabular}

Uncontrolled asthma was associated with older children 13 -14 years as shown in Table 4.

Table 4: Association between respiratory symptoms and age group among school children in Gaborone

\begin{tabular}{|l|l|l|l|l|}
\hline Symptoms & \multicolumn{2}{|l|}{ Age group } & OR $(95 \% \mathrm{Cl}$ & P-value \\
\cline { 1 - 3 } & $\begin{array}{l}13-14 \text { years } \\
(\%) \mathrm{n}=817\end{array}$ & $\begin{array}{l}6-7 \text { years } \\
(\%) \mathrm{n}=358\end{array}$ & & \\
\hline Ever had Wheezing & $228(28)$ & $88(25)$ & $1.1(0.8,1.5)$ & 0.25 \\
\hline Wheezing last 12 months & $137(17)$ & $57(16)$ & $1.06(0.7,1.4)$ & 0.72 \\
\hline $\begin{array}{l}\text { Reported sleep disturbance } \\
\text { due to wheezing }\end{array}$ & $27(3.3)$ & $17(4.7)$ & $0.6(0.3,1.2)$ & 0.24 \\
\hline $\begin{array}{l}\text { Reported limited speech due } \\
\text { to wheezing }\end{array}$ & $49(6.0)$ & $11(3.1)$ & $2.0(1.03,3.9)$ & 0.043 \\
\hline Ever had Asthma & $114(14)$ & $34(9.5)$ & $1.5(1.03,2.3)$ & 0.034 \\
\hline Wheezing during exercise & $273(33)$ & $45(13)$ & $3.4(2.4,4.9)$ & $<0.001$ \\
\hline Dry Cough at night & $209(26)$ & $74(21)$ & $1.3(0.9,1.7)$ & 0.07 \\
\hline Chronic Cough & $106(13)$ & $36(10.1)$ & $1.3(0.8,1.9)$ & 0.16 \\
\hline
\end{tabular}


The older children reported more limited speech due to wheezing $(\mathrm{OR}=2.0,95 \% \mathrm{CI} 1.03,3.91$, $\mathrm{p}$-value $=0.043)$, ever had asthma $(\mathrm{OR}=1.5,95 \%$ CI 1.03, 2.3, p-val$\mathrm{ue}=0.034)$ and wheezing during exercise $(\mathrm{OR}=3.4,95 \%$ CI 2.4, 4.9 p-value $=<0.001)$ compared to the younger children 6-7 years. Other comparisons were not significant as shown in Table 4.
Children from private schools had more wheezing symptoms. They were more likely to have ever wheezed (OR=2.2, 95\% CI 1.6 , 2.9, p-value $<0.0001)$, wheezed in the previous twelve months (have Asthma) (OR=1.6, $95 \%$ CI $1.2,2.3$, p-value $=0.001)$, ever had asthma $(\mathrm{OR}=2.4,95 \% \mathrm{CI} 1.6,3.4$, p-value $<0.0001)$, and wheezed during exercise $(\mathrm{OR}=1.8,95 \%$ CI $1.3,2.4$, p-value < 0.0001). There was no difference in other respiratory symptoms as shown in Table 5.

\section{Table 5: Association of respiratory symptoms and school type (public or private) among children in Gaborone Botswana}

\begin{tabular}{|l|l|l|l|l|}
\hline Symptoms & \multicolumn{2}{|l|}{ School type } & OR (95\% CI) & P-value \\
\hline Ever had Wheezing & Private (\%) & Public (\%) & & \\
\hline Wheezing last 12 months & $121(39)$ & $195(23)$ & $2.2(1.6,2.9)$ & $<0.001$ \\
\hline $\begin{array}{l}\text { Reported disturbance due } \\
\text { to wheezing }\end{array}$ & $10(3.2)$ & $34(3.9)$ & $0.8(0.3,1.6)$ & 0.58 \\
\hline Reported limited speech & $19(6.1)$ & $41(4.7)$ & $1.3(0.7,2.2)$ & 0.34 \\
\hline Ever had Asthma & $64(21)$ & $84(9.7 \%)$ & $2.4(1.6,3.4)$ & $<0.001$ \\
\hline Wheezing during exercise & $113(37)$ & $205(24)$ & $1.8(1.3,2.4)$ & $<0.001$ \\
\hline Dry Cough at night & $86(28)$ & $197(23)$ & $1.3(0.9,1.7)$ & 0.079 \\
\hline Chronic Cough & $33(10.6)$ & $109(13)$ & $0.8(0.5,1.2)$ & 0.42 \\
\hline
\end{tabular}

\section{Discussion}

The main aim of this study was to determine the prevalence of asthma among school children. We used the ISAAC's study approach which an internationally recommended methodology of determining asthma prevalence in children at the community level. We conducted the study on the background of limited data on asthma in Botswana along an increasing worldwide increase. We found a high prevalence of asthma among school children with greater burden and uncontrolled asthma in 1314 year olds and children from private schools.

We report a high prevalence of wheezing in the previous 12 months of $16.5 \%$ among school children in Gaborone. Wheezing in the previous 12 months in our study age group has been used as a proxy measure for asthma ${ }^{13}$. Our finding is similar to that reported in Kenya of $18 \%{ }^{4}$ conducted in a similar context. We found a prevalence of $16.8 \%$ in the $13-14$ year olds which is lower than the one reported in Cape Town of 20\%. Previous work has shown difference in asthma prevalence within the African continent with environmental and life style factors playing the most influence ${ }^{15}$. The background factors such as agricultural lifestyle where children may be exposed to pesticides and situations of environmental pollution provide ground to explain these differences. A so-called western lifestyle has been the factor most commonly cited to explain this worrying increase in asthma prevalence $^{16}$. In essence, this implies a way of life where children are exposed from early infancy to a wide range of foods, infections, indoor and outdoor allergens, and irritants and to the effects of motor vehicle pollution. Botswana is rapidly urbanising with $57.2 \%$ of the population in urban areas with the average annual urban population growth of Gaborone at $1.26 \%$. The high income per capita of up to USD1950 is a proxy indicator of better livelihood and hence western-like style of life. Until fairly recently, children in many African countries lived mainly in rural areas and were not exposed to the effects of a western lifestyle. A study by Thakur N. et al showed 
that background factors are the most important determinants for the occurrence of asthma ${ }^{8}$. Some studies in a limited number of African countries showed a very low rural prevalence of childhood asthma, especially where children lived according to a traditional lifestyle but was more was common in urbanized African children ${ }^{15}$.

We did not find a significant difference in the prevalence of asthma between the older children 13-14 years and their younger counterparts 6-7 years. However, we found that asthma was more severe in the older children than the younger ones as evidenced by limited activity and limited speech. This finding is different from most of the previous work. The study by Lai et al found higher rates of severe asthma among the 6-7 years compared to the 13-14 year olds ${ }^{17,18}$ and this has been reported in the ISAAC phase one manual ${ }^{13}$. With proper care we expect that older children experience less severe asthma disease. Our sample size may have been insufficient to demonstrate this observation.

We found higher burden of asthma in the private schools. We are not able to explain this observation from our study. However, previous work has associated asthma with the higher socio-economic status ${ }^{19}$. The 'hygiene' hypothesis may play a role whereby children from the private schools may be from richer families.

The strength of our study lies in being the first paediatric epidemiological surely on asthma prevalence in Botswana using the ISAAC's study questionnaires that allow for comparison of symptoms that plausibly represent conditions close to asthma in a standardized way. Although cautious interpretation is always advisable, this standardised survey enables substantial advance in our knowledge of the prevalence of asthma in our setting. We however acknowledge the observed low response rate in this study. We did baseline analysis for the non-responders and we do not think they skewed the results of this study. The definition of asthma in an epidemiological study of our nature presents a major challenge. The diagnosis of asth$\mathrm{ma}$ in young children is difficult and based on clinical assessment of symptoms and results of physical examination. We acknowledge that this may not be completely accurate but it has however respiratory wheeze, which has traditionally been used to define asthma in young children $^{20}$. Recall bias and inability to validate the recorded information is a concern. The grading of asthma severity basing on the responses to the questionnaire is not objective enough. However it is an acceptable proxy measure of asthma control. The interpretation of similar symptoms may vary among different people, different cultures \& languages ${ }^{20}$. Parents experience difficulty in understanding terms used by doctors and words in common use were understood differently by these two groups. Most Xhosa words were not in the doctors' vocabulary, and some common English words were not in the parents' vocabulary ${ }^{21}$. We utilised the ISAAC's validated questionnaire with minimum modification and we believe this limited variability in reporting and recording of symptoms.

This study has important policy implications for asthma control. The high burden of asthma in school children with higher severity among the older children provides an opportunity for targeted interventions to improve the quality of life. School asthma education programs would be important to build asthma care skills in schools for nurses and affected students plus parents, Asthma being a chronic disease can adversely affect school performance especially for the older children as they have more severe disease. Mortality would be more likely if not well handled. More work using the video questionnaire is important to validate these observations. There is need to understand parental understanding and interpretation of asthma symptoms in order to formulate appropriate communication messages to the general community. The observation of higher burden of asthma in private schools in Gaborone requires more study.

\section{Conclusion}

The prevalence of Asthma amongst school children in Gaborone, Botswana is high with the older children experiencing more severe asthma disease although the prevalence is similar across the studied age groups. There is a higher burden of asthma in the private schools compared to the public schools.

This study provides baseline data on asthma prevalence in childhood in Gaborone Botswana. Further studies are needed to compare the prevalence of Asthma amongst rural areas versus urban areas in Botswana. 


\section{Acknowledgements}

We acknowledge Chawada Chidzala and Juliet Mbabazi for collection of data and entry.

We thank the Office of Research and Development, University of Botswana for providing the funding for this work.

\section{References}

1. Expert Panel Report 3: Guidelines for the Diagnosis and Management of Asthma. National Institutes of Health. National Heart, Lung and Blood Institute. US Department of Health and Human Services, 2007.

2.The Global Asthma Report 2014. Available from: http://www.globalasthmareport.org/burden/burden. php.

3. Adeloye D, Chan KY, Rudan I, Campbell H. An estimate of asthma prevalence in Africa: a systematic analysis. Croat Med J. 2013;54(6):519-31. PubMed

4. Ait-Khaled N, Odhiambo J, Pearce N, Adjoh KS, Maesano IA, Benhabyles B, et al. Prevalence of symptoms of asthma, rhinitis and eczema in 13- to 14-year-old children in Africa: the International Study of Asthma and Allergies in Childhood Phase III. Allergy. 2007;62(3):247-58. PubMed

5.Yazdanbakhsh M, Kremsner PG, van Ree R. Allergy, parasites, and the hygiene hypothesis. Science. 2002;296(5567):490-4. PubMed

6. Strachan DP. Hay fever, hygiene, and household size. Bmj. 1989;299(6710):1259-60. PubMed

7. Martinez FD. Role of viral infections in the inception of asthma and allergies during childhood: could they be protective? Thorax. 1994;49(12):1189-91. PubMed

8. Thakur N, Oh SS, Nguyen EA, Martin M, Roth LA, Galanter J, et al. Socioeconomic status and childhood asthma in urban minority youths. The GALA II and SAGE II studies. Am J Respir Crit Care Med. 2013;188(10):1202-9. 9. Patel SP, Jarvelin MR, Little MP. Systematic review of worldwide variations of the prevalence of wheezing symptoms in children. Environ Health. 2008;7:57.

10. Worldwide variations in the prevalence of asthma symptoms: the International Study of Asthma and Allergies in Childhood (ISAAC). Eur Respir J. 1998;12(2):31535. PubMed

11. Bacharier LB, Boner A, Carlsen KH, Eigenmann PA,
Frischer T, Gotz M, et al. Diagnosis and treatment of asthma in childhood: a PRACTALL consensus report. Allergy. 2008;63(1):5-34. PubMed

12. Steen TW, Aruwa JE, Hone NM. The epidemiology of adult lung disease in Botswana. Int J Tuberc Lung Dis. 2001;5(8):775-82.

13. Asher M, Keil U, Anderson H, Beasley R, Crane J, Martinez F, et al. International Study of Asthma and Allergies in Childhood (ISAAC): rationale and methods. European respiratory journal. 1995;8(3):483-91.

14. Population and housing census 2011; analytical report Gaborone 2014. Available from:http://countryoffice.unfpa.org/botswana/drive/2011PHCAnalyticalReport.pdf. 15. Weinberg EG. Urbanization and childhood asthma: an African perspective. Journal of allergy and clinical immunology. 2000;105(2):224-31.

16. Weinberg EG. Urbanization and childhood asthma: an African perspective. J Allergy Clin Immunol. 2000;105(2 Pt 1):224-31.

17. BOECHAT JL, RIOS JL, SANT'ANNA CC, FRANCA AT. Prevalence and severity of asthma symptoms in school-age children in the city of Duque de Caxias, Rio de Janeiro, Brazil. J bras pneumol [Internet]. 2005 2016-01-05 [cited 2016 2016-01-05 PubMed ]; 31(2):[111-7 pp.]. Available from: <http://www.scielo.br/scielo.php?script=sci_ arttext\&pid=S1806-37132005000200005\&lng=en\&nrm $=$ iso $>$.

18. Lai CK, Beasley R, Crane J, Foliaki S, Shah J, Weiland S. Global variation in the prevalence and severity of asthma symptoms: phase three of the International Study of Asthma and Allergies in Childhood (ISAAC). Thorax. 2009;64(6):476-83. PubMed

19. Poyser MA, Nelson H, Ehrlich RI, Bateman ED, Parnell S, Puterman A, et al. Socioeconomic deprivation and asthma prevalence and severity in young adolescents. Eur Respir J. 2002;19(5):892-8. PubMed

20. Skytt N, Bonnelykke K, Bisgaard H. "To wheeze or not to wheeze": That is not the question. J Allergy Clin Immunol. 2012;130(2):403-7 e5.

21. Levin ME. Different use of medical terminology and culture-specific models of disease affecting communication between Xhosaspeaking patients and English-speaking doctors at a South African paediatric teaching hospital. S Afr Med J. 2006;96(10):1080-4. 